\title{
Aspirin resistance in the early postoperative period: Pharmacokinetics may be part of the answer
}

\author{
Jacob T. Gutsche, MD, FASE, FCCM, and John G. Augoustides, MD, FASE, FAHA
}

\footnotetext{
From the Cardiovascular and Thoracic Section, Department of Anesthesiology and Critical Care, Perelman School of Medicine, University of Pennsylvania, Philadelphia, Pa.

Financial support: institutional.

Disclosures: Authors have nothing to disclose with regard to commercial support.

Received for publication Aug 26, 2018; revisions received Aug 26, 2018; accepted for publication Aug 27, 2018; available ahead of print Dec 8, 2018.

Address for reprints: John G. Augoustides, MD, FASE, FAHA, Cardiovascular and Thoracic Section, Anesthesi-

ology and Critical Care, Dulles 680, HUP 3400 Spruce St, Philadelphia, PA, 19104-4283 (E-mail: yiandoc@ hotmail.com).

J Thorac Cardiovasc Surg 2019;157:1069-70

$0022-5223 / \$ 36.00$

Copyright (C) 2018 by The American Association for Thoracic Surgery

https://doi.org/10.1016/j.jtcvs.2018.08.127
}

Despite aspirin therapy in the early postoperative period, cardiac surgical patients continue to be at risk for early and clinically important thrombotic events. ${ }^{1,2}$ This aspirin unresponsiveness has prompted platelet function testing to optimize dose adjustment in an effort to achieve therapeutic platelet inhibition timeously and thus escape thrombotic complications. ${ }^{3,4}$ The study by Hattesen and colleagues ${ }^{5}$ in this issue of the Journal sheds light on possible pharmacokinetic mechanisms surgery.

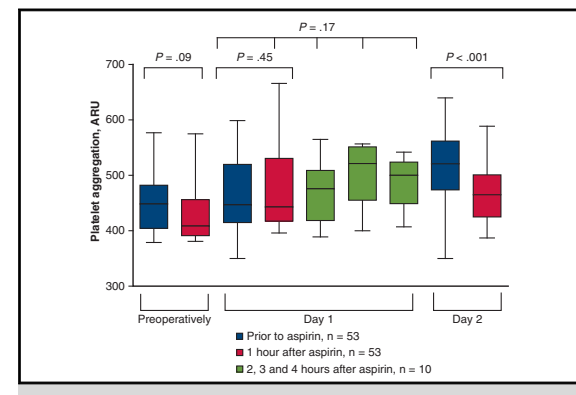

Platelet aggregation levels in the first 2 days after coronary artery bypass grafting

Central Message

The apparent resistance to aspirin early after cardiac surgery may be due to poor gastrointestinal absorption. Therapeutic solutions may include a higher aspirin dose or adding a second agent such as clopidogrel.

See Article page 1059.

for the aspirin resistance observed early after cardiac

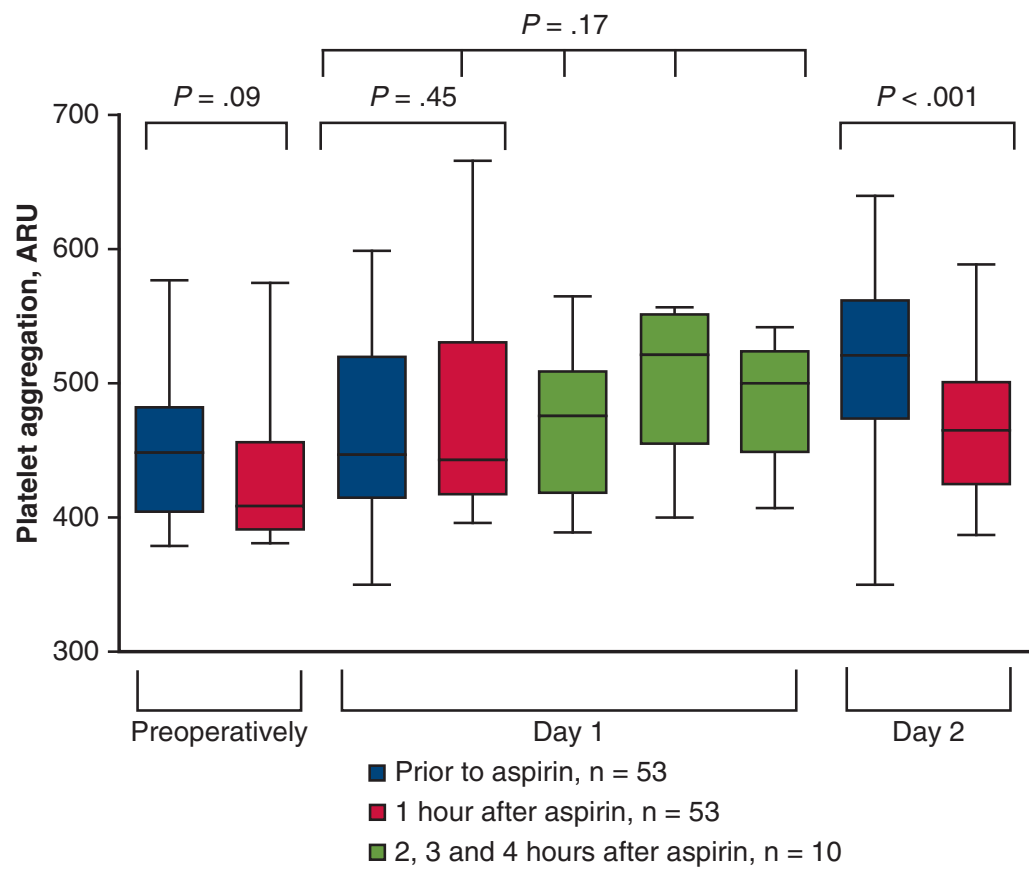

FIGURE 1. Platelet aggregation levels in the first 2 days after coronary artery bypass grafting. $A R U$, aspirin reaction units. Figure 1 for this commentry is taken from the article, Figure 3, $A$ from Hattesen and colleagues, ${ }^{5}$ the subject of this editorial. 
In this study of patients after coronary artery bypass grafting $(N=53)$, the gastrointestinal absorption of aspirin was impaired in the first 48 hours postoperatively as evidenced by low blood levels of salicylic acid and corresponding low levels of platelet inhibition (Figure 1)..$^{5}$ The pharmacokinetics of aspirin returned to the preoperative baseline within 48 hours after surgery with a return of both adequate salicylic acid levels and platelet inhibition. ${ }^{5}$ The investigators measured both free and protein-bound fractions of salicylic acid in the blood to highlight that the low levels of aspirin in the early postoperative period were likely due to reduced gastrointestinal absorption rather than to an increase in protein binding. ${ }^{5}$ This study thus highlights the gastrointestinal pharmacokinetics of aspirin as an important mechanism for apparent "aspirin resistance" in the first days after cardiac surgery. ${ }^{5}$

There has been a focus on aspirin resistance in the Journal in recent years because of its persistent incidence and serious sequelae both in pediatric and adult cardiac surgical practice. ${ }^{1-7}$ This latest trial has focused attention on gastrointestinal absorption as a research and therapeutic target to restore aspirin responsiveness in the early postoperative period for our patients. ${ }^{6}$ Perhaps a higher aspirin dose could enhance absorption and restore a favorable pharmacokinetic profile. ${ }^{3,4}$ Perhaps adding clopidogrel to aspirin therapy even earlier in the postoperative period for dual antiplatelet blockade may provide a solution for adequate platelet blockade, as has been considered already for longer-term outcome enhancement after coronary artery bypass grafting. ${ }^{6,7}$

Hattesen and colleagues ${ }^{5}$ are to be congratulated for highlighting gastrointestinal aspirin kinetics as a new target in their hypothesis-generating study. It seems that in the early postoperative period that an aspirin a day may not be enough for our patients. The opportunities to restore platelet blockade may be best realized through further inquiry to standardize effective platelet blockade in the early postoperative period. ${ }^{8,9}$ Future trials will likely focus on aspirin kinetics as a function of dose and on combination therapy with additional agents such as clopidogrel. Clinical success in this aspect of perioperative care will require freedom from not only thrombotic events but also bleeding events, as the search for the optimal therapeutic approach to balanced platelet blockade in the early postoperative period evolves. $^{7-9}$

\section{References}

1. Emani S, Trainor B, Zurakowski D, Baird CW, Fynn-Thompson FE, Pigula FA, et al. Aspirin unresponsiveness predicts thrombosis in highrisk pediatric patients after cardiac surgery. J Thorac Cardiovasc Surg. 2014;148:810-6.

2. Naimo PS, McGuffin D, Konstantinov IK. Aspirin resistance in the era of personalized medicine: should we not take it personally? J Thorac Cardiovasc Surg. 2015;150:e99-100.

3. Emani S, Zurakowski D, Mulone M, DiNardo JA, Trenor CC, Emani SM. Platelet testing to guide aspirin dose adjustment in pediatric patients after cardiac surgery. J Thorac Cardiovasc Surg. 2017;154:1723-30.

4. Chai PJ. An aspirin a day may not be enough. J Thorac Cardiovasc Surg. 2017; $154: 1714$.

5. Hattesen AL, Modrau IS, Nielsen DV, Hvas AM. The absorption of aspirin is reduced following coronary artery bypass grafting. J Thorac Cardiovasc Surg. 2019; $157: 1059-68$

6. Hage A, Vosine P, Erthal F, Larose E, Glineur D, Chow B, et al. Eight-year followup of the Clopidogrel After Surgery for Coronary Artery Disease (CASCADE) trial. J Thorac Cardiovasc Surg. 2018;155:212-22.

7. Salhiyyah K, Barlow C. Antiplatelet therapy after coronary bypass surgery: 'broken portions' and 'uncertainity' in the search for 'absolute truth'. J Thorac Cardiovasc Surg. 2018;155:223-4.

8. Pakin JS, Hirsh J, Ginsberg JS, Weitz J, Chan NC, Whitlock RP, et al. Once versus twice daily aspirin after coronary bypass surgery: a randomized trial. J Thromb Haemost. 2017; 15:889-96.

9. Zhao Q, Zhu Y, Xu Z, Cheng Z, Mei J, Chen X, et al. Effect of ticagrelor plus aspirin, ticagrelor alone, or aspirin alone on saphenous vein graft patency I year after coronary artery bypass grafting: a randomized clinical trial. JAMA. 2018; 319:1677-86. 